\title{
OBSERVATIONS ON INTRAPLEURAL PRESSURE AND ITS INFLUENCE ON THE RELATIVE CIRCULATION RATE IN EMPHYSEMA
}

\author{
BY WILLIAM B. KOUNTZ, EMMET F. PEARSON AND \\ KARL F. KOENIG \\ (From the Department of Medicine, Washington University, and the Barnes Hospital, \\ St. Louis)
}

(Received for publication June 25, 1932)

In considering the relation of circulatory factors to the hemorespiratory incompetence of emphysema, attention has usually been focused on possible defects in the pulmonary circulation. Less attention has been paid to factors which hinder the return flow of venous blood. Consideration of all the evidence does not seem to justify this emphasis, and the increased intrapleural pressure which has been observed in functional emphysema indicates that the difficulty may arise from changed intrathoracic pressure quite as much as from changes in the lungs themselves.

Evidence from experimental data and inferences from a consideration of the pathology of emphysema support the assumption that when there is obstructed expiration the obvious circulatory impairment is due to change in the lesser circulation. Pathologists agree that there is a diminution in the capillary bed in the lungs in emphysema, a fact which has led to the belief that there must be increased resistance to blood flow through the organ. Friedman and Jackson (1) partially obstructed expiration in dogs and found an increase in the carbon dioxide content of the alveolar air and in the blood. They attributed their results to interference of blood flow through the pulmonary capillaries, a condition supposedly resulting because the intrabronchial pressure was greater than the capillary pressure during the expiratory phase. Heinbecker (2) demonstrated that with inflation of the excised lungs of a cat by positive pressure he could decrease the flow of perfused blood. Lichtheim (3) has shown that the pulmonary capillary bed can be greatly diminished by ligation of the pulmonary artery of one lung with no change in the pulmonary blood pressure.

Kountz, Alexander and Dowell (4) studied the effect of partial obstruction of the expiration of dogs over a period of weeks. They found that as the lungs became larger the intrapleural pressure increased and that venous pressure varied directly with the pressure changes in the pleural cavity. These observations point to the possibility that periph- 
eral factors may be of great importance and that the circulatory disturbances of emphysema may be due to obstruction in the return flow of venous blood. At least they suggest that the effect of intrapleural pressure should be studied before conclusions are drawn concerning the site of the circulatory block.

The only direct observations on the rate of circulation in emphysematous patients were made by Blumgart and Weiss (5). They injected a radioactive substance in the vein of one arm and determined the time required to detect the emanations in the other arm. They found no striking variation from the normal in patients with moderate emphysema but did find a moderate increase in the circulation time in advanced cases of the disease.

The following investigations were designed to offer information concerning the state of the circulation in emphysema and the influence of the altered pressure relations in the chest. The problem was attacked directly in dogs in which an artificially produced emphysematous state existed and in patients as far as experimental methods could be applied.

Intrapleural and venous pressures (White method (6)) were determined in normal subjects and in the same individuals during the performance of a modified Valsalva experiment. Similar determinations were made on emphysematous patients with and without exacerbations of moderate respiratory distress. The circulation rate was determined in normal subjects and in emphysematous patients.

The technic for measuring the intrapleural pressure in patients consisted of having the subject lie on his left side with his right arm above the head and the hips slightly elevated. The chest wall was leveled using a spirit level as a guide. Under novocaine anesthesia a number 16 thoracentesis needle was inserted into the chest and connected to a water manometer. About $35 \mathrm{cc}$. of air were injected into the pleural cavity to keep the lung away from the needle. This quantity caused no change in the manometer reading. As the volume of the respiration influences the intrapleural pressure, it was necessary to have all subjects breathe without force into a tank which measured the expired air. The reading of the intrapleural pressure was also taken in normal subjects when the tidal air became constant at $500 \mathrm{cc}$. Three normal patients were caused to take a deep breath and cautiously make expiratory effort against the closed glottis (Valsalva experiment). The same technic could be followed in moderately dyspneic patients with emphysema but individuals who were extremely dyspneic could not be studied due to the discomfort of the position. In no cases were full expiratory efforts exerted by the individual.

The intrapleural pressure of patients who did not have emphysema was found to average -4 to $-8 \mathrm{~cm}$. of water at the time that the tidal air was $500 \mathrm{cc}$. or less. The peripheral venous pressure of these individuals 
TABLE I

Intrapleural and venous pressures in normal individuals and emphysematous patients

\begin{tabular}{|c|c|c|c|c|c|c|c|c|c|c|}
\hline \multirow[t]{2}{*}{ Patient } & \multirow{2}{*}{$\begin{array}{l}\text { Vital } \\
\text { capac- } \\
\text { ity }\end{array}$} & \multirow{2}{*}{$\begin{array}{c}\text { Tidal } \\
\text { air }\end{array}$} & \multicolumn{2}{|c|}{$\begin{array}{l}\text { Intrapleural } \\
\text { pressure*** } \\
\text { tidal } \\
\text { air }\end{array}$} & \multicolumn{2}{|c|}{$\begin{array}{l}\text { Intrapleural } \\
\text { pressure. } \\
\text { Tidal air } \\
500 \text { cc. }\end{array}$} & \multirow{2}{*}{\begin{tabular}{|c} 
Intra- \\
pleural \\
pres- \\
sure. \\
Val- \\
salva \\
experi- \\
ment
\end{tabular}} & \multirow{2}{*}{$\begin{array}{l}\text { Venous } \\
\text { pres- } \\
\text { sure }\end{array}$} & \multirow{2}{*}{\begin{tabular}{|l} 
Venous \\
pres- \\
sure \\
during \\
asth- \\
matic \\
attack
\end{tabular}} & \multirow{2}{*}{\begin{tabular}{|} 
Venous \\
pres- \\
sure \\
at end \\
of Val- \\
salva \\
experi- \\
ment
\end{tabular}} \\
\hline & & & $\begin{array}{c}\text { Inspira- } \\
\text { tion }\end{array}$ & $\begin{array}{c}\text { Expira- } \\
\text { tion }\end{array}$ & $\underset{\text { tion }}{\text { Inspira- }}$ & $\begin{array}{c}\text { Expira- } \\
\text { tion }\end{array}$ & & & & \\
\hline \multirow{13}{*}{$\begin{array}{l}\text { 1. Normal...... } \\
\text { 2. Normal...... } \\
\text { 3. Normal...... } \\
\text { 4. Emphysema.. } \\
\text { 5. Emphysema. } \\
\text { Asthmatic } \\
\text { attack........ } \\
\text { 6. Emphysema. } \\
\text { Asthmatic } \\
\text { attack....... } \\
\text { 7. Emphysema.. } \\
\text { 8. Emphysema.. } \\
\text { 9. Emphysema.. } \\
\text { 10. Emphysema } \\
\text { (primary } \\
\text { pulmonary } \\
\text { arterial } \\
\text { sclerosis)..... }\end{array}$} & $c c$. & $c c$. & $\underset{\text { water }}{c m .}$ & $\underset{\text { water }}{c m .}$ & $\underset{\text { voater }}{c m .}$ & $\underset{\text { water }}{c m .}$ & $\underset{\text { water }}{c m}$ & $\underset{\text { water }}{c m}$ & $\underset{\text { water }}{c m .}$ & water \\
\hline & 3800 & 375 & -4 & -6 & -5 & -7 & +6 & 4.5 & & 18 \\
\hline & 4200 & 425 & -3 & -7 & -3 & -9 & +8 & 5 & & 16 \\
\hline & 4500 & 480 & -4 & -8 & -4 & -8 & +10 & 5 & & 18 \\
\hline & 4100 & 380 & -2 & -5 & & & +12 & 6 & 10 & 14 \\
\hline & & & & & & & & & & \\
\hline & 2200 & 200 & +2 & -8 & & & & & 10 & 12 \\
\hline & & & & & & & & & & \\
\hline & 1900 & 300 & +4 & -3 & & & & & 14 & 14 \\
\hline & 3200 & 225 & -1 & -6 & -3 & -9 & & 6.5 & 7 & \\
\hline & 2700 & 300 & -2 & -4 & -2 & -6 & & 6 & & \\
\hline & 2800 & 270 & -1 & -4 & & & & & & \\
\hline & 1700 & 200 & +2 & -8 & & & & 14 & & \\
\hline
\end{tabular}

* All intrapleural pressures taken in mid-axillary line in 5th interspace.

averaged $5.5 \mathrm{~cm}$. of water by the White method. The intrapleural pressure of the same patients when moderate expiratory effort was made against the closed glottis averaged $+8 \mathrm{~cm}$. of water. Venous pressure in the normal individuals increased to $18 \mathrm{~cm}$. of water. Emphysematous patients in whom there was no evidence of respiratory distress usually were found to have, during expiration, intrapleural pressures which were nearer to atmospheric pressure than the normal. In these patients the venous pressures averaged $7 \mathrm{~cm}$. of water, which is at the upper limit of normal range. One patient who suffered respiratory distress from an asthmatic attack and whose vital capacity was 50 per cent of his estimated normal had an intrapleural pressure of +4 to $-3 \mathrm{~cm}$. of water with tidal air of $300 \mathrm{cc}$. His venous pressure was $14 \mathrm{~cm}$. Two other patients during mild asthmatic attacks had intrapleural pressures of +2 to -8 and -1 to -6 . The venous pressure in these patients was 10 and 7 respectively. After subsidence of the attack the venous pressure decreased somewhat but did not become less than $6 \mathrm{~cm}$. of water.

The intrapleural pressure in chronic emphysema was found to vary over different areas of the lung. Thus, in two cases over the upper lobe it was less negative than over the base as noted from the following figures. 
TABLE II

Variation of intrapleural pressure over different areas of the chest in emphysema

\begin{tabular}{l|c|c|c|c|c}
\hline \hline \multirow{2}{*}{$\begin{array}{c}\text { Patient } \\
\text { number }\end{array}$} & $\begin{array}{c}\text { Tidal } \\
\text { air }\end{array}$ & $\begin{array}{c}\text { Intrapleural pressure, lower border of } \\
\text { scapula }\end{array}$ & \multicolumn{2}{|c}{$\begin{array}{c}\text { Upper border of } \\
\text { scapula }\end{array}$} \\
\cline { 3 - 6 } & & Inspiration & Expiration & Inspiration & Expiration \\
\hline & $c c$. & $c m$. water & $c m$. water & cm. water & cm. water \\
$10 \ldots . .$. & 300 & -6 & -2 & -3 & +1 \\
$11 \ldots . .$. & 350 & -5 & -3 & -3 & +2 \\
\hline
\end{tabular}

The venous pressures of a group of asthmatics entering the hospital were taken at least twice every day and occasionally, when the attacks were frequent, more observations were made. It was found that the venous pressures rose during the attacks and fell afterwards. In those asthmatic patients whose chest presented very little evidence of emphysema the venous pressure fell immediately, but in cases where a marked emphysema was present the venous pressure dropped more slowly. Sometimes several days were required for a return to a normal range.

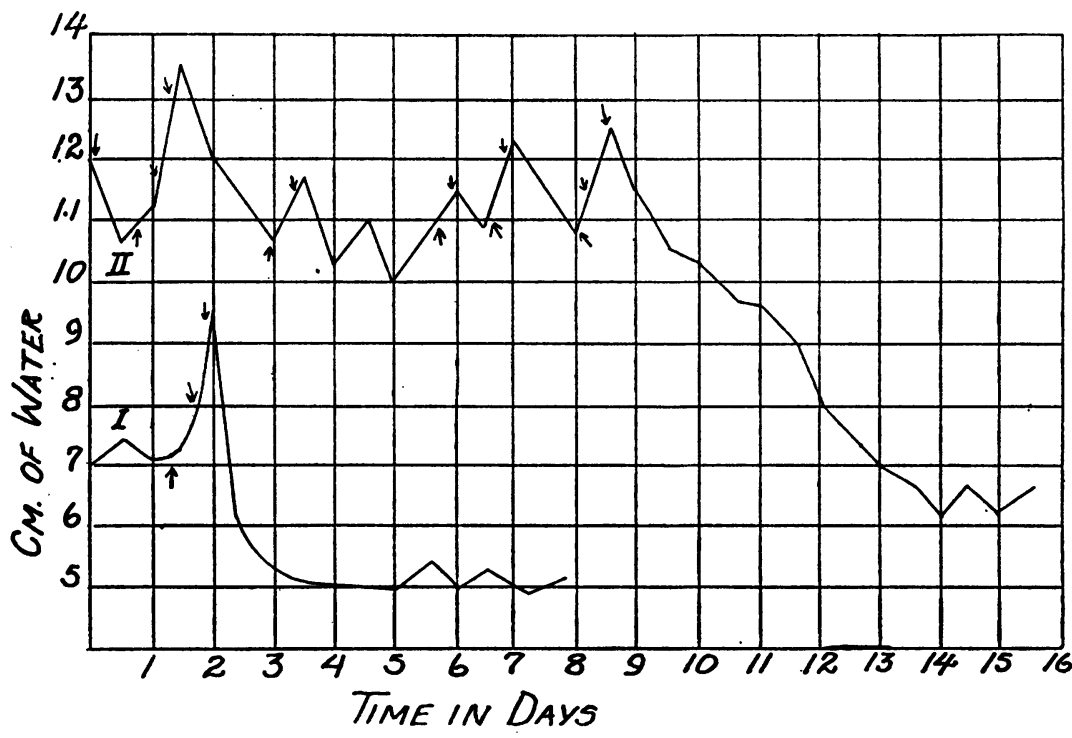

Chart I

I. Record of the Venous Pressure of an Asthmatic Individual Who Had Only a Mild Degree of Emphysema.

The venous pressure immediately dropped to normal after an asthmatic attack. Arrow up indicates onset of attack. Arrow down indicates an injection of adrenalin.

II. Record of the Venous Pressure in an Asthmatic Individual with EMPHYSEMA.

The venous pressure returned to normal much more slowly after the attacks ceased than in number I. Arrows up indicate attacks. Arrows down indicate adrenalin. 
The relative circulation rate was determined in normal subjects and in emphysematous patients by the method devised by Hamilton, Moore, Kinsman, and Spurling (7). A dye, phenoltetraiodophthalein sodium (6 milligrams per kilogram of body weight), was injected into a cubital vein, and blood was simultaneously collected from the brachial artery of the other arm into small glass tubes containing heparin, which were mounted about the periphery of a moving drum. A number 20 short beveled Luer needle was used for the arterial puncture and the blood was run directly into the tubes. The time of the injection of the dye was

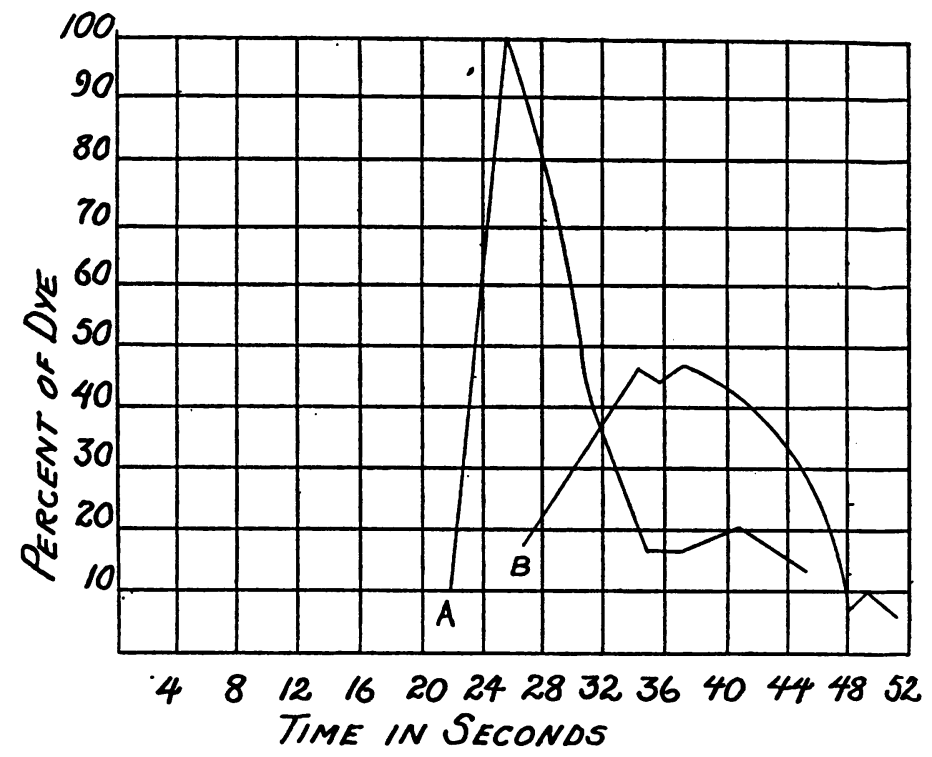

Chart II

Concentration Wave of Dye Injected into the Median Cubital Vein of ONe Arm and Removed from the Brachial Artery of the Other.

(A) Normal man. Pulse rate 67. (B) Asthmatic with moderate obstruction to breathing. Pulse rate 70. The standard for the curve was the maximum concentration of dye in the serum of the normal.

electrically recorded on the kymograph by a break switch attached to the injecting syringe. Time was recorded by a chronograph. The tubes containing the blood were centrifuged and a drop of 10 per cent sodium hydroxide was added to the serum from each tube to bring out the purple color of the dye. In this way the time required for the dye to reach the first tube was determined. By comparison of the dye in the succeeding tubes with a known standard, a "concentration wave" of the dye as it passed the collecting point in its first circuit could be plotted as described by the originators of the method. 
They found the normal circulation time to be approximately 23 seconds with a pulse rate of 72 . In two normals we found the circulation time to be 23 and 22 seconds with a pulse rate of 74 and 76 . In one patient with extreme emphysema and a pulse rate of 72 the circulation time was 28 seconds or 5 seconds above the average normal. In three patients with moderate emphysema the circulation time was 24,23 , and 25 seconds respectively; the pulse rates, however, were more rapid. In two patients who had emphysema without demonstrable functional changes the circulation time was well within the normal range.

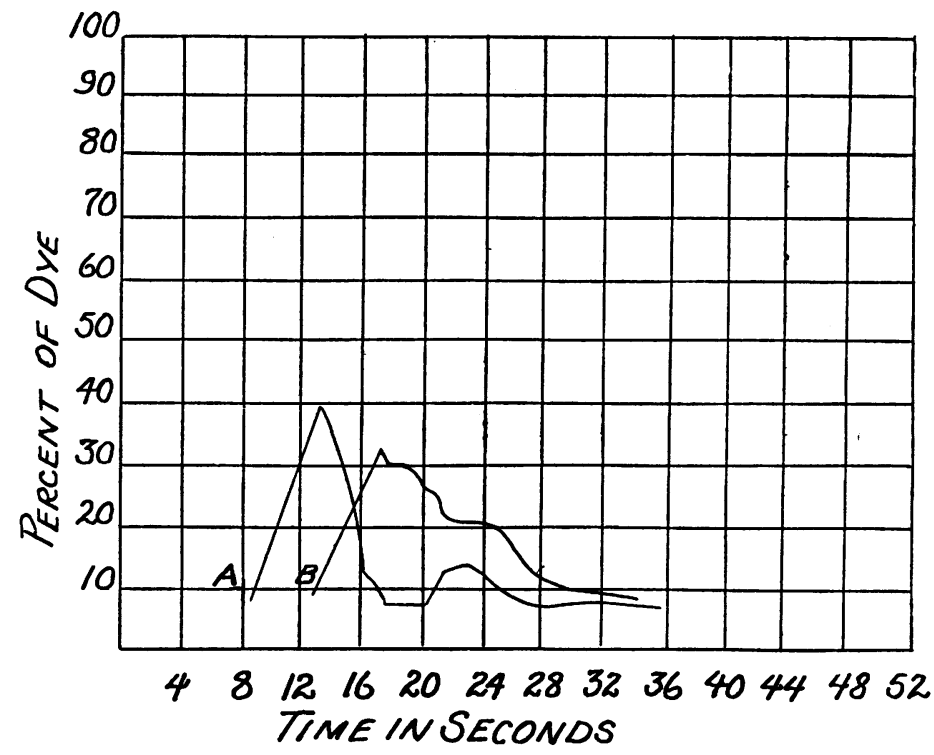

Chart III

Concentration Wave of Dye Injected into the Femoral Vein of a Dog AND REMOVED FRom the Right HeArT.

(A) Dog in normal state under amytal anesthesia. (B) Same dog made emphysematous by a ball valve in trachea. A prolongation of 4 seconds in the appearance of the dye in the emphysematous animal.

The circulation time studies were carried out in dogs and an attempt was made to determine the point of the relative obstruction to the circulation that occurs in high grade emphysema. The method of injecting the dye $(500 \mathrm{mgm}$. in all dogs) and collecting the blood was similar to that employed with patients. In one group of dogs the dye was injected into the femoral vein of one leg and the blood collected from the femoral artery of the other leg. In the next group the dye was injected into the femoral vein and collected from the right heart. In the third group the dye was injected into the right heart and collected from a femoral artery. Amytal anesthesia was used. Glass arterial cannulae were used when 
blood was collected from the femoral arteries and the blood was directed into the collecting tubes by a glass tube $10 \mathrm{~cm}$. in length. A number 16 Luer needle was used both for injection of the dye into and for collection of blood from the right heart. The cardiac taps were made in the 7th interspace on the right side of the sternum with the needle directed upwards in order to strike the right ventricle. When blood was collected from the right heart it was necessary to have the dog swinging above the collecting tubes with the chest downward.

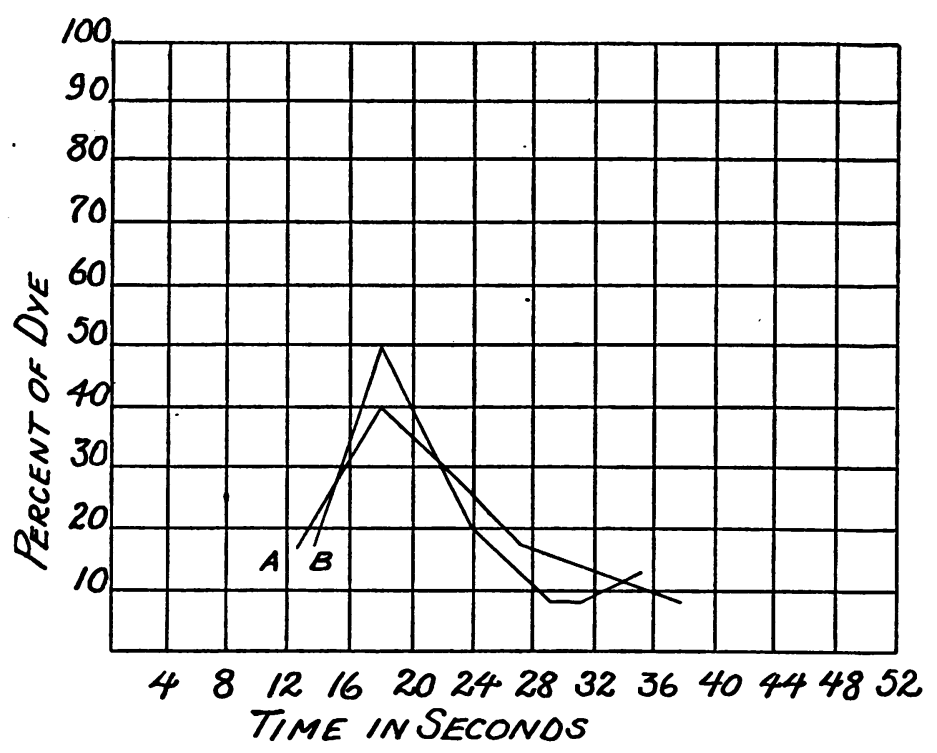

Chart IV

Concentration Wave of Dye Injected into the Right Heart and Removed from the Femoral Artery.

(A) Emphysematous animal. (B) Normal animal. There was no delay in appearance of first tube of dye and the waves were similar in character. Pulse rates were the same.

The dogs were allowed to recuperate and after a period of three to four weeks their lungs were distended by inserting an adjustable valve in the trachea which obstructed expiration (4). An emphysematous condition was thus produced in the animals and the circulation rate was again determined using the same point of injection and collection. A difficulty in the use of the method in some animals arose from the increase in heart rate from the asphyxia which occurred during the production of emphysema. Slowing of the heart rate under amytal anesthesia, however, was the usual result obtained. The dye was injected when the heart rate was normal. The effect of asphyxia on the heart muscle and consequently on the cardiac output could not be determined. Kountz 
and Hammuda (8) have shown that slowing of the heart in asphyxia precedes by some time a diminution in cardiac output.

There was a prolonged period of circulation time of two seconds or more in the groups in which the dye was injected into the femoral vein and collected from the femoral artery and from the right heart. The concentration curve had a less sharp apex and there was a more prolonged period of high concentration after the production of distention. The group in which the dye was injected into the right heart showed no delay in the time appearance of the dye in the first tube when the animals were made emphysematous.

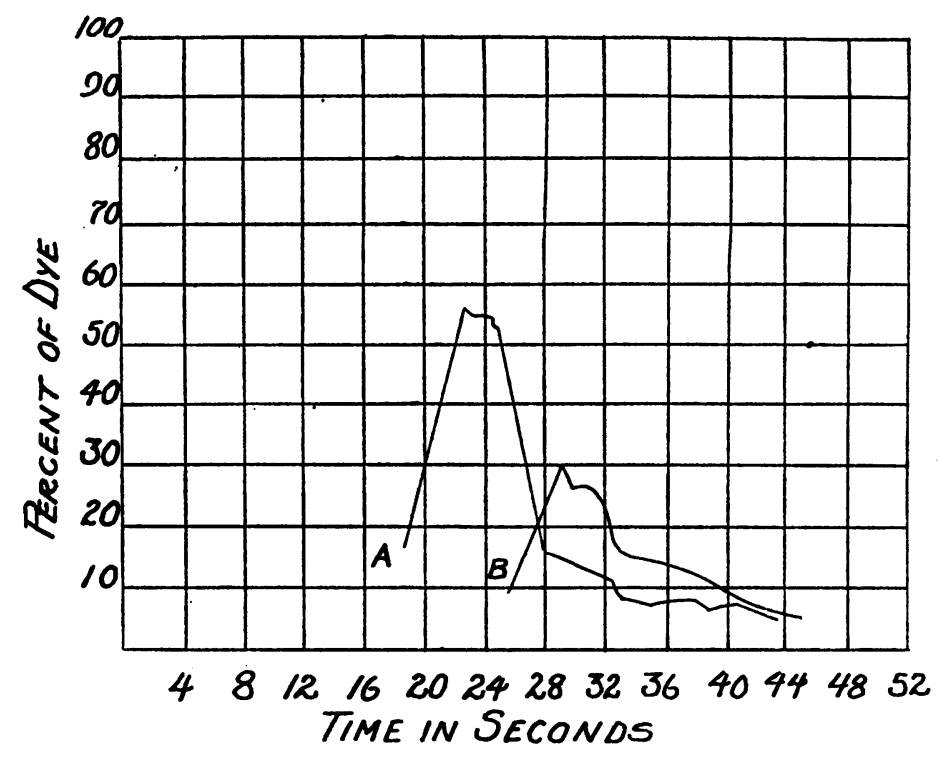

Chart V

Concentration Waye of Dye Injected into the Left Femoral Vein and Removed from the Right Femoral Artery.

$(A)$ Animal in normal state under amytal anesthesia. (B) Animal made emphysematous-under amytal anesthesia. Note prolongation of circulation of $6 \frac{1}{2}$ seconds and a change in the concentration curve. Heart rate 90 to 94 respectively.

\section{DISCUSSION}

It is extremely difficult to separate the various factors operative in the functional pathology of emphysema. Hoover (9) and others have elaborated on the important effects of decreased vital capacity and increased residual air. Friedmann and Jackson (1) were first to question the authority of those who believed that the respiratory difficulties provided the, entire explanation for the hemorespiratory incompetence. These authors believed that there is impairment in the circulation in emphysema but they, like subsequent investigators, mentioned only the possibility of blockage of the circulation in the lungs. 
We found by clinical and experimental observations on the venous and intrapleural pressures in obstructive emphysematous conditions and by determination of the circulation rate that there is a relative obstruction to the flow of blood into the thorax when the vital capacity is low. Many other observations support this view.

It is known that the heart decreases in size during the Valsalva experiment. If the obstruction were in the lungs, this experiment should cause an increase in the size of the heart. The inference must be that the circulation is obstructed before it reaches the right heart. We have found an increase in venous pressure and intrapleural pressure during this experiment. Furthermore, Dolley and Weise (10) have shown by increasing the intrapleural pressure with a closed pneumothorax that the flow of lymph into the chest may be diminished 50 per cent.

The same phenomena as observed during the Valsalva experiment have been shown to exist in emphysematous patients but to a less striking degree. In general there is a parallelism between venous and intrapleural pressures in emphysematous patients with exacerbations and remissions of respiratory distress and both pressures remain above normal in extreme cases. Furthermore, Alexander, Luten, and Kountz (11) have shown that there is no more tendency to right sided cardiac hypertrophy in long standing emphysematous patients than in other people of the same age group. The above facts indicate that the load on the right heart is probably not increased in emphysema and therefore the theoretical resistance in the lesser circulation probably does not exist.

The experiments which have been performed by others on excised lungs and which show an increase in perfusion pressure when intrabronchial pressure is increased are not of value in interpreting the actual conditions in the intact thorax. Any type of pressure exerted on the excised lungs would not be compensated by other pressure relations. There is no intrapleural pressure effect and the circulation is not intact.

By direct study of the circulation in dogs the physiological principles involved in emphysema became more apparent. It was found that as distention of the lungs in the experimental animal was produced there was first a drop and then a rise of the intrapleural pressure. This has recently been confirmed by Brill and associates (12). A rise of the venous pressure accompanied a rise of the intrapleural pressure. An increase in the time of the circulation rate was constantly found. In the experiments the circulation rates seem to offer evidence concerning the site of obstruction but must be interpreted with caution. A prolonged period of 2 or more seconds occurred between the points of injection and recovery when the point of entrance to the thorax intervened and there was an increase in dilution of the dye before it was collected. This dilution is explained by greater diffusion of the dye due to a condition of relative venous stasis. On the other hand, when the dye was injected 
into the right heart and carried only through the pulmonary circulation before it was recovered at the periphery no variations in the time and only a slight variation in the concentration wave of the dye occurred after the dogs were made emphysematous.

It seems impossible to explain the results on the basis of obstruction in the pulmonary circuit. If this were the site of block, the dilution should have been equally as great when the dye was injected into the right ventricle. Dilution under these circumstances, however, may have been influenced by factors other than circulation time, and the relative volume and rigidity of the venous bed on the one hand and of the right ventricle on the other introduce influences which cannot be accurately evaluated.

It has been shown that in the absence of heart failure or direct obstruction to venous return the venous pressure is a rough index to the intrapleural pressure. The peripheral venous pressure has been shown to rise appreciably during an asthmatic paroxysm. The rate of return to normal varies. In patients who have elastic lungs the venous pressure returns to the normal range quickly after the cessation of the asthmatic attack the same as it does after the Valsalva experiment. In patients who have marked emphysema with asthma the fall is slow, and the original level may never be reached. We believe that this is due to the relative inelasticity of the lungs when emphysema is present, a feature which is perhaps fundamental to the development of permanent increased intrapleural pressure. The relative high intrapleural pressure over the apex of the lungs in chronic emphysema perhaps accounts for the prominence of veins of the upper portion of the body so characteristic in this disease.

\section{SUMMARY}

1. The intrapleural and peripheral venous pressures are found to be increased in functional obstructive emphysema. In the experimental animal with obstruction to expiration in the trachea there is an upward trend of both pressures after the lungs are distended. Either clinically or experimentally a rise in the intrapleural pressure is found to reflect directly upon the venous pressure.

2. When dye is injected into a peripheral vein and removed from an artery in obstructive emphysema or in an experimental animal whose lungs were distended to a point of full inspiration an increase in the circulation time was noted. Dye injected into the right heart in the experimental animal and removed from an artery showed no delay in the circulation time although some evidence existed to indicate that the right heart did not empty itself as quickly as it did under normal circumstances.

3. It is suggested that although there may have been some obstruction to a normal amount of blood passing through the lungs, the chief obstruction was at or peripheral to the entrance of the blood into the thorax. Certainly the delay occurred before the blood reached the right heart. 


\section{BIBLIOGRAPHY}

1. Friedman, E. D. and Jackson, H. C., Arch. Int. Med., 1917, xix, 767. The $\mathrm{CO}_{2}$ content of blood and of alveolar air in obstructed expiration.

2. Heinbecker, P., Am. J. Physiol., 1927, lxxxi, 170. The mechanism of the respiratory waves in systemic arterial blood pressure.

3. Lichtheim quoted by Rehfisch. Deutsche med. Wchnschr., 1918, xliv, 277. Zur Aetologie der Vergrösserung der rechten Herzkammer, insbesondere bei behinderter Nasenatmung.

4. Kountz, W. B., Alexander, H. L., and Dowell, D., J. Am. Med. Assoc., 1929, xciii, 1369. Emphysema simulating cardiac decompensation.

5. Blumgart, H. L., and Weiss, S., Trans. Assoc. Am. Phys., 1926, xli, 294. Clinical observations on the velocity of blood flow in auricular fibrillation and in emphysema.

6. White, Harvey Lester, Am. J. Physiol., 1924, lxix, 10. Observations on venous pressure and skin blanching pressure by a modified method.

7. Hamilton, W. F., Moore, J. W., Kinsman, J. M. and Spurling, R. G., Am. J. Physiol., 1928, lxxxiv, 338. Simultaneous determination of the pulmonary and systemic circulation times in man and of a figure related to the cardiac output.

8. Kountz, W. B., and Hammuda, M., Am. Heart J., In Press. Effect of asphyxia and anoxemia on the electrocardiogram.

9. Hoover, C. F., Arch. Int. Med., 1913, xi, 52. The minute volume and alveolar air in pulmonary emphysema.

10. Dolley, F. S. and Wiese, E. R., Arch. Surg., 1929, xviii, 542. Effects of a large closed pneumothorax on thoracic lymph flow.

11. Alexander, H. L., Luten, D., and Kountz, W. B., J. Am. Med. Assoc., 1927, lxxxviii, 882. The effects on the heart of long standing bronchial asthma.

12. Brill, S., and Leake, C. D., Proc. Soc. Exper. Biol. and Med., 1930, xxvii, 518. Effects of typical broncho-dilating drugs on the intrapleural pressure. 